\title{
Retailer's Optimal Payment Decisions for Price-dependent Demand under Partial Advance Payment and Trade Credit in Different Scenarios.
}

\author{
Rajesh Gupta $^{1}$, Snigdha Banerjee ${ }^{2}$ and Swati Agrawal ${ }^{3 *}$ \\ ${ }^{1}$ Department of Computer Applications, Prestige Institute of Management, Gwalior, India \\ ${ }^{2}$ School of Statistics, D A University, Vigyan Bhawan, Khandwa Road, Indore, India \\ $3^{3 *}$ Department of Mathematics, M.B. Khalsa College, Indore, India \\ *Corresponding Author: swati_ag_14@yahoo.co.in
}

Available online at: www.isroset.org

Accepted 12/Aug/2018, Online 30/Aug/2018

\begin{abstract}
In this paper, we investigate retailer's payment decisions in an EOQ framework for a supply chain system under trade credit and partial advance payment. Considering price-dependent demand, the model has been developed under three different scenarios. In Scenario I, the optimal length of the replenishment cycle is determined when the supplier specifies the discount factor for the advance payment to be made by the retailer and the retailer's has a fixed mark-up. In Scenario II, retailer's optimal selling price is determined for the fixed length of the replenishment cycle and discount factor specified by the supplier. In Scenario III, discount factor is optimally decided by the retailer for specified retailer's selling price and the fixed length of the replenishment cycle. In all the three scenarios, the retailer's payment has to be made at two different stages: partial advance payment at the time of placing the order prior to beginning of the selling season and the remaining dues have to be paid at the end of permitted trade credit period with an objective to maximize the retailer's net profit. Numerical examples are presented. It is seen that the retailer's net profit is maximum when the retailer can decide his selling price.
\end{abstract}

Key words- Inventory, supply chain, trade credit, discounted advance payment, price-dependent demand.

\section{INTRODUCTION}

In a competitive market, in order to stimulate the product demand, supplier generally offers a certain interest free credit period to the retailer. Although for this period, no interest is charged by the supplier, once this period is over, a high rate of interest is charged by the supplier on the remaining dues.

Trade credit has emerged as one of the key factors of business transactions in the current scenario. Trade credit or permissible delay in payment reduces the retailer's initial investment and hence his holding cost - leading to some reduction in his total costs. When the delay in payment of the purchased items is for the entire lot, the policy is known as a full-trade credit policy. When the retailer is asked by the supplier for a portion of the payment in advance of the delivery of goods, and then for the remaining balance, the supplier sets a permissible delay period, the policy is called a partial-trade credit policy.

Trade credit financing for inventory policy was first formulated by Haley and Higgins where they studied the relationship between inventory policy and credit policy [1] Chapman et al. derived an economic order quantity model which considers possible credit periods allowable by suppliers [2]. Their model is seen to be highly sensitive to the length of the credit period as well as to the relationship between the credit period and inventory level. Goyal developed the mathematical model for interest-free credit period permitted by the supplier. In case the account is not settled by the end of the credit period the supplier charges high interest while the retailer can earn some interest on the revenue earned during the credit period [3].

Later on more researchers conducted comprehensive and detailed studies on the payment policy. Jaggi and Aggarwal studied credit financing in economic ordering policies of deteriorating items on the basis of Goyal's study [4]. Khouja and Mehrez studied the model where the supplier's credit policy is linked to the order quantity [5]. Cheng et al. further presented the retailer's optimal inventory policy under different supplier credit policies [6].

In this paper, we add the aspect of advance payment that has been ignored by most studies of inventory models with credit period and mainly review the literatures from three aspects, namely, discount strategy, inventory policy, and the advance payment to the supplier.

Ouyang et al., Goyal et al., Ho et al., Sana and Chaudhuri developed models considering two-part trade credit [7-10]. 
Skouri et al. generalized the model for deteriorating items with ramp-type demand and permissible delay in payments [11]. Chern et al. discussed Nash equilibrium solution in a vendor-buyer supply chain with trade credit financing [12].

Taleizadeh et al. and Guria et al. considered an EOQ problem under partial delayed payment [13-14]. Wu and Chan study an EOQ inventory model with full and partial trade credit policies for deteriorating items [15]. Chen et al. considered the situation where the supplier offers full and partial delayed payment depending on order quantity [16].

Offering trade credit sometimes leads to some disadvantages, one of them being that the suppliers do not receive cash immediately and this may lead to a supply crunch.

In order to address this issue another strategy practised in the market is of advance payment. Due to the reduction in cash flow and financial complications at the supplier's end, the supplier may demand advance payment. Advance payment and its influences on inventory decisions have got little consideration in the inventory literature.

Zhang considered advance payment with fixed per-payment costs to derive the optimal cash deposit [17]. Maiti et al. studied an inventory model with advance payment in stochastic environment with price-dependent demand over a finite time horizon [18]. Taleizadeh et al. developed inventory model for products having constant demand under uncertainty with discount and prepayment [19]. Thangam incorporated advance payment scheme and two-echelon trade credits into an EOQ model for perishable items with constant demand [20]. Taleizadeh et al. developed a constrained multiproduct EOQ model for decaying item with prepayment and fuzzy demand [21]. Taleizadeh et al. considered an inventory control model with constant demand including multiple advance payments and partial backordering [22]. This work was further extended by Taleizadeh et al. by considering delayed payment [23]. Zhang et al. developed an EOQ model with constant demand having two types of advance payment, i.e., all payment paid in advance and partial advance payment [24]. Taleizadeh presented an EOQ model for evaporating items with constant demand under multiple equal-sized advance payments with and without partial backordering, respectively [25, 26]. Pourmohammad and Taleizadeh presented an inventory model with constant demand both partial advanced and partial delayed payments with full backordering [27]. For constant demand ,Lashgari et al. presented a three-echelon supply chain model and used the EOQ policy with partial downstream delayed payment and partial upstream advanced payment from the buyer's perspective [28]. Taleizadeh studied impact of capital cost in lot sizing model with advance payment and supply disruptions when shortages are partially backordered [29].
$\mathrm{Wu}$ et al. explored an inventory model with price-sensitive demand, when the seller requests an advance-cash-credit (ACC) payment for perishable products with expiration dates [30]. Recently, Li et al. with payment time sensitive demand rate explored replenishment policy and payment term among ACC payment from the seller's perspective [31].

As discussed above, the lot-sizing problem under discounted partial advance payment and trade credit has not yet been studied in many plausible scenarios. In most of the previous work, demand has been considered as constant with different payment strategy under trade credit policy. Moreover, none of these articles consider advance payment scheme with trade credit without cash discount where either fixed or partial pre-payment or the discount rate as being decided by the retailer. In this article, we try to fill up this lacuna by considering retailer's payment decisions for pricedependent demand under partial advance payment with discount and trade credit in different scenarios. In this article all scenarios considered are applicable and used in realworld situations with a spectrum of simple available options.

The proposed study considers the retailer's inventory model under three different scenarios as explained in section 3 . We consider the situation when the retailer is required to pay all his dues by the end of the credit period. The retailer's payment decision is modeled in terms of values of the proportion of payment to be made at two different stages: Advance payment and at the end of permitted delay in payment provided by the supplier with an objective to maximize the retailer's net profit. Numerical examples are provided to demonstrate the developed model. Analysis on optimal solution with respect to key parameters has been carried out and the results are discussed.

The rest of the paper is organized as follows: In Section II, the notations and assumptions are presented. The mathematical models to maximize the net profit rate are formulated under three scenarios followed by solution methodology comprising some useful theoretical results to find the optimal solution is presented in Section III. Numerical examples are provided in Section IV. Finally, we present the conclusion and future scope in Section V.

\section{NOTATIONS AND ASSUMPTIONS}

The following notations are used in this paper.

$\mathrm{P}_{\mathrm{S}} \quad$ supplier's unit selling price.

$P_{R} \quad$ retailer's unit selling price $\left(P_{R}>P_{S}\right)$. (decision variable)

D retailer's selling price-dependent demand. $D=\alpha P_{R}{ }^{-\beta}$, $\alpha>0, \beta>0$. 
$\rho \quad$ discount factor for advance booking, $0<\rho<1$.

(decision variable)

Percent discount $=100(1-\rho)$

h unit inventory holding cost per unit time.

A ordering cost per order.

$\mathrm{I}_{\mathrm{PR}} \quad$ interest rate per unit time paid by retailer for loan.

$\mathrm{I}_{\mathrm{ER}} \quad$ interest rate earned per unit time earned by retailer.

$\mathrm{M}_{\mathrm{A}} \quad$ retailer's advance period specified by the supplier.

$M_{R} \quad$ retailer's credit period specified by the supplier.

Q retailer's order quantity per cycle (decision variable). $\mathrm{Q}=\mathrm{DT}$.

$\mathrm{A}_{1} \quad$ proportion of $\mathrm{Q}$ for which an advance payment is paid by the retailer at epoch $\mathrm{T}_{0}, \mathrm{M}_{\mathrm{A}}$ time units prior to the epoch 0 when the selling season begins.

$\mathrm{T}$ the retailer's replenishment cycle length (decision variable).

Net retailer's net profit per unit time.

* With any decision variable or Net indicates its optimal value.

\section{Assumptions}

The mathematical model is developed with the following assumptions:

1. The supplier provides a fixed credit period $M_{R}$ to settle the accounts to the retailer.

2. The end consumer market demand rate is a decreasing function of the retailer's selling price, $D\left(P_{R}\right)=\alpha P_{R}^{-\beta}$, where $\alpha>0$ is a scaling factor and $\beta>0$ is the index of price elasticity. For simplicity, $\mathrm{D}\left(\mathrm{P}_{\mathrm{R}}\right)$ and $\mathrm{D}$ will be used interchangeably in this paper.

3. $A_{1}$ is considered to be a function of $\rho$ and defined as $A_{1}=a e^{-b(\rho-c)^{2}}$ where $a, b$ and $c$ are constants.

4. The retailer starts selling the goods as soon as he receives it.

5. The retailer withdraws the accumulated earnings only at epoch T.

6. For the payments made to the supplier at $M_{A}$ and $M_{R}$ (If $\left.M_{R}<T\right)$, the retailer has to take loan from the financial institution like banks.

7. Shortages are not allowed.

8. The replenishment rate and time horizon are infinite.

\section{MODEL}

The model is developed with stated discount advance period under trade credit by the supplier to the retailer with price dependent demand so as to maximize the net profit per unit time for the retailer under three different scenarios. :

In Scenario I, optimal length of the replenishment cycle is determined when the discount factor for the advance payment by retailer is specified by the supplier and the retailer's selling price is known. In Scenario II, retailer's optimal selling price is determined for the fixed length of the replenishment cycle and discount factor specified by the supplier. In Scenario III, discount factor is optimally decided by the retailer for specified retailer's selling price and the fixed length of the replenishment cycle. In all the three scenarios, the retailer's payment has to be made at two different stages: partial advance payment at the time of placing the order before the beginning of the selling season and the remaining dues to be paid at the end of permitted delay period with an objective to maximize the retailer's net profit.

The retailer orders for $\mathrm{Q}$ units of inventory before the beginning of the selling season at epoch $t_{0}, M_{A}$ time units prior to the beginning of the season. The ordered units arrive at the beginning of the selling season. Credit period of length $M_{R}$ is provided from the time of delivery of goods. The payments for the ordered units are made by the retailer under three different scenarios in two parts:

1. An advance payment at epoch $\mathrm{M}_{\mathrm{A}}$ for proportion $\mathrm{A}_{1}$ of $\mathrm{Q}$ units is made at the discounted rate $\rho \mathrm{P}_{\mathrm{S}} .0 \leq \mathrm{A}_{1} \leq 1$.

2 . For the remaining quantity, payment has been to be made under the two cases.

Case I: $\mathrm{M}_{\mathrm{R}} \leq \mathrm{T}$

In this case a payment at the rate $\mathrm{P}_{\mathrm{S}}$ for proportion $\left(1-\mathrm{A}_{1}\right)$ of $\mathrm{Q}$ units is made with loan from financer at the epoch $\mathrm{M}_{\mathrm{R}}$. No interest to be paid to the retailer for this delayed payment under the credit period.

Inventory Level

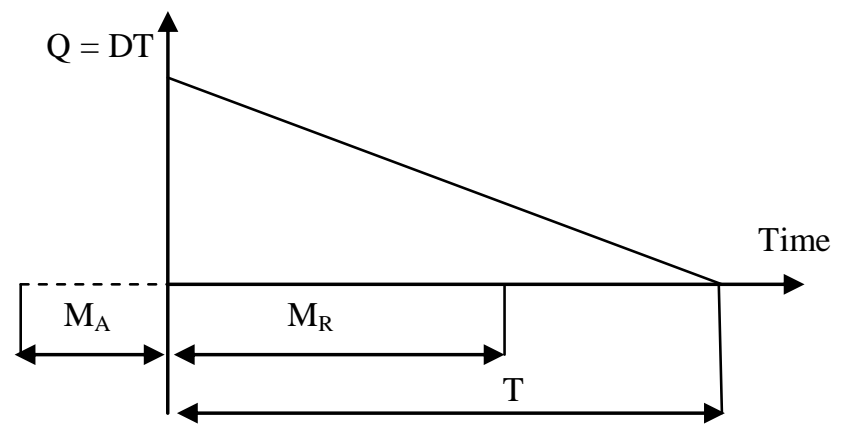

At epoch $\mathrm{M}_{\mathrm{A}},\left(\mathrm{A}_{1} \mathrm{Q}\right)$ of $\quad$ At epoch $\mathrm{M}_{\mathrm{R}},\left(1-\mathrm{A}_{1}\right) \mathrm{Q}$ of amount to be paid with amount to be paid with loan interest through loan@ $\mathrm{I}_{\mathrm{PR}} @ \mathrm{I}_{\mathrm{PR}}$

Figure 1(a): Inventory -time graph and trade credit in inventory model under advance payment when $M_{R} \leq T$ 


\section{Case II: $\mathrm{M}_{\mathrm{R}}>\mathrm{T}$}

In this case, a payment for the remaining proportion $\left(1-A_{1}\right)$ of $Q$ units to be made at the rate $P_{S}$, at epoch $M_{R}>T$ in order to take advantage of the credit period. No interest is to be paid for this payment since the credit period $M_{R}$ is greater than the cycle length $T$. In this case, the payment at $M_{R}$ is made by the retailer from his sales revenues and interest earned.

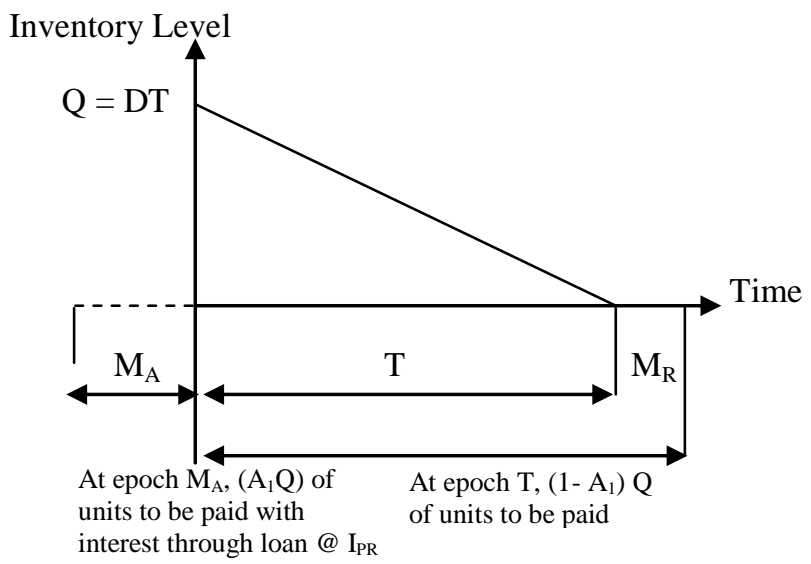

Figure 1(b): Inventory -time graph and trade credit in inventory model under advance payment when $M_{R}>T$

Loan taken by the retailer for the payment made at $\mathrm{M}_{\mathrm{A}}$ and $M_{R}\left(M_{R}<T\right)$ will be repaid to the financer with interest at the rate $I_{P R}$ at epoch $T$. The retailer starts selling his goods from the beginning of the selling season. The sales earnings up to $\mathrm{T}$ are invested as they accumulate to earn interest at the rate $\mathrm{I}_{\mathrm{ER}}$. At the end of the selling season, the payment to the supplier is made from the sales as well as interest earned up to $\mathrm{T}$.

\subsection{Formulation of Mathematical Model}

The retailer's net profit per unit time is given by

Net $=\frac{1}{\mathrm{~T}}($ Total revenue earned $-($ Ordering cost + Stock holding cost + Purchase cost + Interest paid)

where

Total revenue earned $=$ Sales revenue + Interest earned

Ordering cost is A

Stock holding cost per cycle is $\frac{\mathrm{h}\left(\mathrm{DT}^{2}\right)}{2}$

The total revenue earned, interest paid and other cost components for Case I and Case II are as follows:

Case I: $\mathrm{M}_{\mathrm{R}} \leq \mathrm{T}$
The total purchasing cost, that is, the sum of costs paid at epochs $M_{A}$ and $M_{R}$ for quantities $\left(A_{1} Q\right)$ and $\left(1-A_{1}\right) Q$ respectively is:

$\left(\rho P_{S}\right)\left(A_{1} Q\right)+(1-A 1) Q$

The interest paid by the retailer for the amount paid at the epoch $\mathrm{M}_{\mathrm{A}}$ and $\mathrm{M}_{\mathrm{R}}$, till $\mathrm{T}$ is $\left(\mathrm{T}+\mathrm{M}_{\mathrm{A}}\right)\left(\mathrm{A}_{1} \mathrm{Q}\right)\left(\rho \mathrm{P}_{\mathrm{S}}\right) \mathrm{I}_{\mathrm{PR}}+$ $\left(T-M_{R}\right)\left(1-A_{1}\right) Q_{S} I_{P R}$

Total revenue earned by the retailer is

$\mathrm{P}_{\mathrm{R}} \mathrm{DT}\left(1+\frac{\mathrm{TI}_{\mathrm{ER}}}{2}\right)$

Hence the retailer's net profit per unit time is

Net1 $=P_{R} D\left(1+\frac{T I_{E R}}{2}\right)-\frac{A}{T}-\frac{1}{2} h D T-\rho P_{S} A_{1} D[1+$
$\left.\left(T+M_{A}\right) I_{P R}\right]-P_{S}\left(1-A_{1}\right) D\left[1+\left(T-M_{R}\right) I_{P R}\right]$

Case II: $\mathrm{M}_{\mathrm{R}}>\mathrm{T}$

The total purchasing cost paid at epochs $\mathrm{M}_{\mathrm{A}}$ and $\mathrm{T}$ for quantities $\left(\mathrm{A}_{1} \mathrm{Q}\right)$ and $\left(1-\mathrm{A}_{1}\right) \mathrm{Q}$ respectively is

$\left(\rho P_{S}\right)\left(A_{1} Q\right)+P_{S}\left(1-A_{1}\right) Q$

The interest paid by the retailer to the financer till epoch $\mathrm{T}$ for the amount paid at the epoch $\mathrm{M}_{\mathrm{A}}$ is

$\left(T+M_{A}\right)\left(A_{1} Q\right)\left(\rho P_{S}\right) I_{P R}$

Total revenue and interest earned by the retailer is

$P_{R}(D T)+\frac{P_{R}(D T) I_{E R} T}{2}+P_{R}(D T)\left(M_{R}-T\right) I_{E R}$

Hence the retailer's net profit per unit time is

Net2 $=P_{R} D\left[1+\left(M_{R}-\frac{T}{2}\right) I_{E R}\right]-\frac{A}{T}-\frac{h D T}{2}+P_{S} D\left[A_{1}[1-\right.$ $\left.\left.\rho\left(1+\left(M_{A}+T\right) I_{P R}\right)\right]-1\right]$

The retailer's overall net profit per unit time is

Net $=\left\{\begin{array}{l}\text { Net1; for } M_{R} \leq T \\ \text { Net2; for } M_{R}>T\end{array}\right.$

\subsection{Analysis}

\subsubsection{Model analysis for Scenario I}

In this scenario, $\rho$ and $P_{R}$ are fixed and $T$ is the decision variable.

The analysis of the net profit function for Case I and Case II are presented to obtain the optimal value of the decision variable. 


\section{Necessary and sufficient conditions for scenario I,}

The first order (necessary) conditions for maximization of Netj with respect to $\mathrm{T}$ are

$\frac{\partial \mathrm{Netj}}{\partial \mathrm{T}}=0 ; \quad \mathrm{j}=1,2$.

Differentiating (1) and (2) with respect to $\mathrm{T}$ we get respectively

$\frac{\partial \text { Net } 1}{\partial \mathrm{T}}=-\frac{\mathrm{Dh}}{2}+\frac{\mathrm{A}}{\mathrm{T}^{2}}+\frac{1}{2} \mathrm{DI}_{\mathrm{ER}} \mathrm{P}_{\mathrm{R}}-\mathrm{DI}_{\mathrm{PR}}\left(1-\mathrm{A}_{1}\right) \mathrm{P}_{\mathrm{S}}-$

$\mathrm{D} \rho \mathrm{I}_{\mathrm{PR}} \mathrm{A}_{1} \mathrm{P}_{\mathrm{S}}$

and

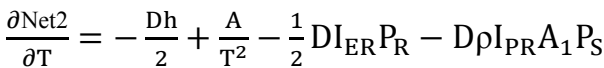

where

$\mathrm{D}=\alpha \mathrm{P}_{\mathrm{R}}^{-\beta}$

As the decision variable $\rho$ affects the proportion $A_{1}$, we assume that

$\mathrm{A}_{1}=\mathrm{ae}^{-\mathrm{b}(\rho-\mathrm{c})^{2}}$

On equating (4) and (5) to zero we get respectively

$\mathrm{T}_{1}^{*}=\frac{\sqrt{2 \mathrm{~A}}}{\sqrt{\mathrm{D}\left(\mathrm{h}-\mathrm{I}_{\mathrm{ER}} \mathrm{P}_{\mathrm{R}}+2 \rho \mathrm{I}_{\mathrm{PR}} \mathrm{P}_{\mathrm{S}}\left(1-\mathrm{A}_{1}+\rho \mathrm{A}_{1}\right)\right)}}$

and

$\mathrm{T}_{2}{ }^{*}=\frac{\sqrt{2 \mathrm{~A}}}{\sqrt{\mathrm{D}\left(\mathrm{h}+\mathrm{I}_{\mathrm{ER}} \mathrm{P}_{\mathrm{R}}+2 \rho \mathrm{I}_{\mathrm{PR}} \mathrm{A}_{1} \mathrm{P}_{\mathrm{S}}\right)}}$

The Second order (sufficiency) conditions for Netj, $\mathrm{j}=1,2$ to be maximum with respect to $\mathrm{T}$ is

i.e. $\frac{\partial^{2} \mathrm{Netj}}{\partial \mathrm{T}^{2}}<0$

Differentiating (4) and (5) with respect to T given $P_{R}$ and $\rho$ we get respectively

$\frac{\partial^{2} \mathrm{Net} 1}{\partial \mathrm{T}^{2}}=-\frac{2 \mathrm{~A}}{\mathrm{~T}^{2}}<0$

and

$\frac{\partial^{2} \mathrm{Net} 2}{\partial \mathrm{T}^{2}}=-\frac{2 \mathrm{~A}}{\mathrm{~T}^{2}}<0$

Thus, Net1 and Net2 are both concave functions of $\mathrm{T}$ and there exists a unique optimal value of $\mathrm{T}$ at which maximum value of Net will be attained.

\subsubsection{Model analysis for Scenario II}

In this scenario, $\rho$ and $T$ are fixed and $\mathrm{P}_{\mathrm{R}}$ is the decision variable.

In order to obtain the optimal values of the decision variables, analysis of the net profit functions for Case I and Case II are presented below:

\section{Necessary and sufficient conditions for scenario II}

The first order (necessary) conditions for maximization of Netj with respect to $P_{R}$

$\frac{\partial \mathrm{Netj}}{\partial \mathrm{P}_{\mathrm{R}}}=0 \mathrm{j}=1,2$.

Differentiating (1) and (2) with respect to $P_{R}$ given $T$ and $\rho$ we get respectively

$\frac{\partial \mathrm{Net1}}{\partial \mathrm{P}_{\mathrm{R}}}=\left(1+\frac{\mathrm{TI}_{\mathrm{ER}}}{2}\right)\left(\mathrm{P}_{\mathrm{R}} \frac{\partial \mathrm{D}}{\partial \mathrm{P}_{\mathrm{R}}}+\mathrm{D}\right)-\frac{\partial \mathrm{D}}{\partial \mathrm{P}_{\mathrm{R}}}\left\{\frac{1}{2} \mathrm{hT}+\right.$
$\left.\mathrm{P}_{\mathrm{S}} \rho \mathrm{A}_{1}\left[1+\left(\mathrm{T}+\mathrm{M}_{\mathrm{A}}\right) \mathrm{I}_{\mathrm{PR}}\right]+\mathrm{P}_{\mathrm{S}}\left(1-\mathrm{A}_{1}\right)\left[1+\left(\mathrm{T}-\mathrm{M}_{\mathrm{R}}\right) \mathrm{I}_{\mathrm{PR}}\right]\right\}$

$\frac{\partial \mathrm{Net} 2}{\partial \mathrm{P}_{\mathrm{R}}}=\left(1+\left(\mathrm{M}_{\mathrm{R}}-\frac{\mathrm{T}}{2}\right) \mathrm{I}_{\mathrm{ER}}\right)\left(\mathrm{P}_{\mathrm{R}} \frac{\partial \mathrm{D}}{\partial \mathrm{P}_{\mathrm{R}}}+\mathrm{D}\right)-\frac{1}{2} \mathrm{hT} \frac{\partial \mathrm{D}}{\partial \mathrm{P}_{\mathrm{R}}}+$

$\mathrm{P}_{\mathrm{S}} \frac{\partial \mathrm{D}}{\partial \mathrm{P}_{\mathrm{R}}}\left[\mathrm{A}_{1}\left[1-\rho\left(1+\left(\mathrm{M}_{\mathrm{A}}+\mathrm{T}\right) \mathrm{I}_{\mathrm{PR}}\right)\right]-1\right]$

Where using (6), we obtain

$\frac{\partial \mathrm{D}}{\partial \mathrm{P}_{\mathrm{R}}}=-\alpha \beta \mathrm{P}_{\mathrm{R}}^{-(\beta+1)}$

Therefore, substituting from (14) in (12) and (13), we obtain respectively

$\frac{\partial \mathrm{Net} 1}{\partial \mathrm{P}_{\mathrm{R}}}=\left(1+\frac{\mathrm{TI}_{\mathrm{ER}}}{2}\right) \alpha \mathrm{P}_{\mathrm{R}}^{-\beta}(1-\beta)+\alpha \beta \mathrm{P}_{\mathrm{R}}^{-(\beta+1)}\left[\frac{1}{2} \mathrm{hT}+\right.$

$\left.P_{S}\left\{\rho A_{1}\left[1+\left(T+M_{A}\right) I_{P R}\right]+\left(1-A_{1}\right)\left[1+\left(T-M_{R}\right) I_{P R}\right]\right\}\right]$

$\frac{\partial \mathrm{Net} 2}{\partial \mathrm{P}_{\mathrm{R}}}=$

$\left[1+\left(\mathrm{M}_{\mathrm{R}}-\frac{\mathrm{T}}{2}\right) \mathrm{I}_{\mathrm{ER}}\right] \alpha \mathrm{P}_{\mathrm{R}}^{-\beta}(1-\beta)+\alpha \beta \mathrm{P}_{\mathrm{R}}^{-(\beta+1)}\left[\frac{1}{2} \mathrm{hT}-\right.$

$\left.\mathrm{P}_{\mathrm{S}}\left[\mathrm{A}_{1}\left[1-\rho\left(1+\left(\mathrm{M}_{\mathrm{A}}+\mathrm{T}\right) \mathrm{I}_{\mathrm{PR}}\right)\right]-1\right]\right]$

On equating (15) and (16) to zero we get respectively

$\mathrm{P}_{\mathrm{R} 1}{ }^{*}=\frac{1}{(\beta-1)\left(2+\mathrm{TI}_{\mathrm{ER}}\right)} \beta\left(\mathrm{hT}+2 \mathrm{P}_{\mathrm{S}}\left[\rho \mathrm{A}_{1}\left(1+\left(\mathrm{T}+\mathrm{M}_{\mathrm{A}}\right) \mathrm{I}_{\mathrm{PR}}\right)+\right.\right.$

$\left.\left.\left(1-A_{1}\right)\left(1+\left(T-M_{R}\right) I_{P R}\right)\right]\right)$

$\mathrm{P}_{\mathrm{R} 2}{ }^{*}=\frac{-\beta\left[\mathrm{hT}+2 \mathrm{P}_{\mathrm{S}}\left(1-\mathrm{A}_{1}+\mathrm{A}_{1} \rho\left(1+\left(\mathrm{M}_{\mathrm{A}}+\mathrm{T}\right) \mathrm{I}_{\mathrm{PR}}\right)\right)\right]}{(\beta-1)\left(\mathrm{TI}_{\mathrm{ER}}-2 \mathrm{I}_{\mathrm{ER}} \mathrm{M}_{\mathrm{R}}-2\right)}$

The Second order (sufficiency) conditions for Netj, $\mathrm{j}=1,2$ to be maximum with respect to $P_{R}$ is

i.e. $\frac{\partial^{2} \mathrm{Netj}}{\partial \mathrm{P}_{\mathrm{R}}{ }^{2}}<0$ 
Differentiating (12) and (13) with respect to $P_{R}$ given $T$ and $\rho$ we get respectively

$\frac{\partial^{2} \mathrm{Net} 1}{\partial \mathrm{P}_{\mathrm{R}}{ }^{2}}=\left(\frac{2 \partial \mathrm{D}}{\partial \mathrm{P}_{\mathrm{R}}}+\mathrm{P}_{\mathrm{R}} \frac{\partial^{2} \mathrm{D}}{\partial \mathrm{P}_{\mathrm{R}}{ }^{2}}\right)\left(1+\frac{\mathrm{T} \mathrm{I}_{\mathrm{ER}}}{2}\right)-\frac{\partial^{2} \mathrm{D}}{\partial \mathrm{P}_{\mathrm{R}}{ }^{2}}\left\{\frac{1}{2} \mathrm{hT}+\right.$ $\left.\rho \mathrm{P}_{\mathrm{S}} \mathrm{A}_{1}\left[1+\left(\mathrm{T}+\mathrm{M}_{\mathrm{A}}\right) \mathrm{I}_{\mathrm{PR}}\right]+\mathrm{P}_{\mathrm{S}}\left(1-\mathrm{A}_{1}\right)\left[1+\left(\mathrm{T}-\mathrm{M}_{\mathrm{R}}\right) \mathrm{I}_{\mathrm{PR}}\right]\right\}$ (19)

$\frac{\partial^{2} \mathrm{Net} 2}{\partial \mathrm{P}_{\mathrm{R}}{ }^{2}}=\left(2 \frac{\partial \mathrm{D}}{\partial \mathrm{P}_{\mathrm{R}}}+\mathrm{P}_{\mathrm{R}} \frac{\partial^{2} \mathrm{D}}{\partial \mathrm{P}_{\mathrm{R}}{ }^{2}}\right)\left(1+\left(\mathrm{M}_{\mathrm{R}}-\frac{\mathrm{T}}{2}\right) \mathrm{I}_{\mathrm{ER}}\right)-$ $\frac{1}{2} \mathrm{hT} \frac{\partial^{2} \mathrm{D}}{\partial \mathrm{P}_{\mathrm{R}}{ }^{2}}+\mathrm{P}_{\mathrm{S}} \frac{\partial^{2} \mathrm{D}}{\partial \mathrm{P}_{\mathrm{R}}{ }^{2}}\left[\mathrm{~A}_{1}\left[1-\rho\left(1+\left(\mathrm{M}_{\mathrm{A}}+\mathrm{T}\right) \mathrm{I}_{\mathrm{PR}}\right)\right]-1\right]$

where using (14), we obtain

$\frac{\partial^{2} \mathrm{D}}{\partial \mathrm{P}_{\mathrm{R}}^{2}}=\alpha \beta(\beta+1) \mathrm{P}_{\mathrm{R}}^{-(\beta+2)}$

Since at $\mathrm{P}_{\mathrm{R} 1}{ }^{*}, \frac{\partial \mathrm{Net1}}{\partial \mathrm{P}_{\mathrm{R}}}=0$,

$\frac{\partial^{2} \mathrm{Net} 1}{\partial \mathrm{P}_{\mathrm{R}}^{2}}=$

$\left(\frac{2 \partial \mathrm{D}}{\partial \mathrm{P}_{\mathrm{R}}}+\mathrm{P}_{\mathrm{R}} \frac{\partial^{2} \mathrm{D}}{\partial \mathrm{P}_{\mathrm{R}}^{2}}\right)\left(1+\frac{\mathrm{T} \mathrm{I}_{\mathrm{ER}}}{2}\right)-\frac{\partial^{2} \mathrm{D}}{\partial \mathrm{P}_{\mathrm{R}}^{2}}\left\{\frac{\left(\mathrm{P}_{\mathrm{R}} \frac{\partial \mathrm{D}}{\partial \mathrm{P}_{\mathrm{R}}}+\mathrm{D}\right)\left(1+\frac{\mathrm{T} \mathrm{I}_{\mathrm{ER}}}{2}\right)}{\frac{\partial \mathrm{D}}{\partial \mathrm{P}_{\mathrm{R}}}}\right\}$

$=\left\{\left(2 \frac{\partial \mathrm{D}}{\partial \mathrm{P}_{\mathrm{R}}}+\mathrm{P}_{\mathrm{R}} \frac{\partial^{2} \mathrm{D}}{\partial \mathrm{P}_{\mathrm{R}}^{2}}\right)-\frac{\partial^{2} \mathrm{D}}{\partial \mathrm{P}_{\mathrm{R}}^{2}}\left[\left(\mathrm{P}_{\mathrm{R}} \frac{\partial \mathrm{D}}{\partial \mathrm{P}_{\mathrm{R}}}+\mathrm{D}\right)\left(\frac{\partial \mathrm{D}}{\partial \mathrm{P}_{\mathrm{R}}}\right)^{-1}\right]\right\}(1+$

$\left.\frac{\mathrm{T} \mathrm{I}_{\mathrm{ER}}}{2}\right)$

$=\left\{2 \frac{\partial \mathrm{D}}{\partial \mathrm{P}_{\mathrm{R}}}-\mathrm{D} \frac{\partial^{2} \mathrm{D}}{\partial \mathrm{P}_{\mathrm{R}}^{2}} / \frac{\partial \mathrm{D}}{\partial \mathrm{P}_{\mathrm{R}}}\right\}\left(1+\frac{\mathrm{T} \mathrm{I}_{\mathrm{ER}}}{2}\right)$

where using (14) and (21), we obtain

$\frac{\partial^{2} \mathrm{Net} 1}{\partial \mathrm{P}_{\mathrm{R}}{ }^{2}}=(1-\beta) \alpha \mathrm{P}_{\mathrm{R}}^{-(\beta+1)}\left(1+\frac{\mathrm{TI}_{\mathrm{ER}}}{2}\right)$

Here, $\frac{\partial^{2} \text { Net1 }}{\partial \mathrm{P}_{\mathrm{R}}{ }^{2}}<0 \quad$ at $\mathrm{P}_{\mathrm{R} 1}{ }^{*}$ iff $1-\beta<0$ i.e., $\beta>1$.

Also, since at $\mathrm{P}_{\mathrm{R} 2}{ }^{*}, \frac{\partial \mathrm{Net} 2}{\partial \mathrm{P}_{\mathrm{R}}}=0$,

$\frac{\partial^{2} \mathrm{Net} 2}{\partial \mathrm{P}_{\mathrm{R}}{ }^{2}}=\left(2 \frac{\partial \mathrm{D}}{\partial \mathrm{P}_{\mathrm{R}}}+\mathrm{P}_{\mathrm{R}} \frac{\partial^{2} \mathrm{D}}{\partial \mathrm{P}_{\mathrm{R}}{ }^{2}}\right)\left(1+\left(\mathrm{M}_{\mathrm{R}}-\frac{\mathrm{T}}{2}\right) \mathrm{I}_{\mathrm{ER}}\right)-$

$\frac{\partial^{2} \mathrm{D}}{\partial \mathrm{P}_{\mathrm{R}}{ }^{2}}\left\{\frac{\left(1+\left(\mathrm{M}_{\mathrm{R}}-\frac{\mathrm{T}}{2}\right) \mathrm{I}_{\mathrm{ER}}\right)\left(\mathrm{P}_{\mathrm{R}} \frac{\partial \mathrm{D}}{\partial \mathrm{P}_{\mathrm{R}}}+\mathrm{D}\right)}{\frac{\partial \mathrm{D}}{\partial \mathrm{P}_{\mathrm{R}}}}\right\}$

$=\left[\left(2 \frac{\partial \mathrm{D}}{\partial \mathrm{P}_{\mathrm{R}}}+\mathrm{P}_{\mathrm{R}} \frac{\partial^{2} \mathrm{D}}{\partial \mathrm{P}_{\mathrm{R}}{ }^{2}}\right)-\frac{\partial^{2} \mathrm{D}}{\partial \mathrm{P}_{\mathrm{R}}{ }^{2}}\left\{\frac{\left(\mathrm{P}_{\mathrm{R}} \frac{\partial \mathrm{D}}{\partial \mathrm{P}_{\mathrm{R}}}+\mathrm{D}\right)}{\frac{\partial \mathrm{D}}{\partial \mathrm{P}_{\mathrm{R}}}}\right\}\right]\left(1+\left(\mathrm{M}_{\mathrm{R}}-\right.\right.$

$\left.\left.\frac{\mathrm{T}}{2}\right) \mathrm{I}_{\mathrm{ER}}\right)$

$=\left(2 \frac{\partial \mathrm{D}}{\partial \mathrm{P}_{\mathrm{R}}}-\frac{\partial^{2} \mathrm{D}}{\partial \mathrm{P}_{\mathrm{R}}{ }^{2}} \mathrm{D}\left(\frac{\partial \mathrm{D}}{\partial \mathrm{P}_{\mathrm{R}}}\right)^{-1}\right)\left(1+\left(\mathrm{M}_{\mathrm{R}}-\frac{\mathrm{T}}{2}\right) \mathrm{I}_{\mathrm{ER}}\right)$

where using (14) and (21), we obtain $\frac{\partial^{2} \mathrm{Net} 2}{\partial \mathrm{P}_{\mathrm{R}}{ }^{2}}=(1-\beta) \alpha \mathrm{P}_{\mathrm{R}}^{-(\beta+1)}\left(1+\left(\mathrm{M}_{\mathrm{R}}-\frac{\mathrm{T}}{2}\right) \mathrm{I}_{\mathrm{ER}}\right)$

Here, $\frac{\partial^{2} \mathrm{Net} 2}{\partial \mathrm{P}_{\mathrm{R}}{ }^{2}}<0$ for $1-\beta<0$ i.e., $\beta>1$.

Hence, if $\beta>1$, both Net1 and Net 2 are concave function of $P_{R}$. Hence there exists a unique optimal value of $P_{R 1}^{*}$ and $\mathrm{P}_{\mathrm{R} 2}^{*}$

\subsubsection{Model analysis for Scenario III}

In this scenario, $\mathrm{P}_{\mathrm{R}}$ and $\mathrm{T}$ are fixed and $\rho$ is the decision variable.

In order to obtain the optimal values of the decision variables, analysis of the net profit functions for Case I and Case II is presented below:

\section{Necessary and sufficient conditions for scenario III}

The first order (necessary) conditions for maximization of Netj with respect to $P_{R}$ are

$\frac{\partial \mathrm{Netj}}{\partial \rho}=0 \quad \mathrm{j}=1,2$.

Differentiating (1) and (2) with respect to $\rho$ given $T$ and $P_{R}$, we get, respectively,

$\frac{\partial \text { Net1 }}{\partial \rho}=\mathrm{P}_{\mathrm{S}} \mathrm{D}\left\{\frac{\partial \mathrm{A}_{1}}{\partial \rho}\left[1+\left(\mathrm{T}-\mathrm{M}_{\mathrm{R}}\right) \mathrm{I}_{\mathrm{PR}}\right]-\left[1+\left(\mathrm{M}_{\mathrm{A}}+\right.\right.\right.$

T) $\left.\left.I_{P R}\right]\left(A_{1}+\rho \frac{\partial A_{1}}{\partial \rho}\right)\right\}$

$\frac{\partial \mathrm{Net} 2}{\partial \rho}=\mathrm{P}_{\mathrm{S}} \mathrm{D} \frac{\partial \mathrm{A}_{1}}{\partial \rho}-\mathrm{P}_{\mathrm{S}} \mathrm{D}\left(1+\left(\mathrm{M}_{\mathrm{A}}+\mathrm{T}\right) \mathrm{I}_{\mathrm{PR}}\right)\left(\mathrm{A}_{1}+\rho \frac{\partial \mathrm{A}_{1}}{\partial \rho}\right)$

We consider $A_{1}=a e^{-b(\rho-c)^{2}}$

where $\frac{\partial \mathrm{A}_{1}}{\partial \rho}=-2 \mathrm{ab}(\rho-\mathrm{c}) \mathrm{e}^{-\mathrm{b}(\rho-c)^{2}}$

On equating (26) and (27) to zero and using (28) and (29), we get, respectively

$\rho_{1}{ }^{*}=\frac{1}{2\left(1+\left(\mathrm{T}+\mathrm{M}_{\mathrm{A}}\right) \mathrm{I}_{\mathrm{PR}}\right)}\left(\left[1+\left(\mathrm{T}-\mathrm{M}_{\mathrm{R}}\right) \mathrm{I}_{\mathrm{PR}}\right]+\mathrm{c}[1+\right.$ $\left.\left.\left(\mathrm{M}_{\mathrm{A}}+\mathrm{T}\right) \mathrm{I}_{\mathrm{PR}}\right]\right)-$

$\frac{1}{4 b\left(1+\left(T+M_{A}\right) I_{P R}\right)} \sqrt{\begin{array}{c}4 b^{2}\left(\left[1+\left(T-M_{R}\right) I_{P R}\right]+c\left[1+\left(M_{A}+T\right) I_{P R}\right]\right)^{2} \\ \left(2 b c\left[1+\left(T-M_{R}\right) I_{P R}\right]-\left[1+\left(T+M_{A}\right) I_{P R}\right]\right)\end{array}}$

and

$\rho_{2}{ }^{*}=\frac{1}{2\left(1+\left(\mathrm{T}+\mathrm{M}_{\mathrm{A}}\right) \mathrm{I}_{\mathrm{PR}}\right)}\left[1+\mathrm{c}\left(1+\left(\mathrm{T}+\mathrm{M}_{\mathrm{A}}\right) \mathrm{I}_{\mathrm{PR}}\right)\right]-$

$\frac{1}{4 b\left(1+\left(T+M_{A}\right) I_{P R}\right)} \sqrt{\begin{array}{c}8 b\left(1+\left(M_{A}+T\right) I_{P R}-2 b c\right)\left(1+\left(M_{A}+T\right) I_{P R}\right) \\ -2 b^{2}\left[1+c\left(1+\left(M_{A}+T\right) I_{P R}\right)\right]^{2}\end{array}}$ 
The Second order (sufficiency) conditions for Netj, $\mathrm{j}=1,2$ to be maximum with respect to $\rho$ is

i.e. $\frac{\partial^{2} \mathrm{Netj}}{\partial \rho^{2}}<0$

Differentiating (26) and (27) with respect to $\rho$ given $T$ and $P_{R}$ we get respectively

$$
\begin{aligned}
& \frac{\partial^{2} \mathrm{Net} 1}{\partial \rho^{2}}=\mathrm{P}_{\mathrm{S}} \mathrm{D}\left\{\left[1+\left(\mathrm{T}-\mathrm{M}_{\mathrm{R}}\right) \mathrm{I}_{\mathrm{PR}}\right] \frac{\partial^{2} \mathrm{~A}_{1}}{\partial \rho^{2}}-\left[1+\left(\mathrm{M}_{\mathrm{A}}+\right.\right.\right. \\
& \left.\left.\mathrm{T}) \mathrm{I}_{\mathrm{PR}}\right]\left(2 \frac{\partial \mathrm{A}_{1}}{\partial \rho}+\rho \frac{\partial^{2} \mathrm{~A}_{1}}{\partial \rho^{2}}\right)\right\} \\
& =\mathrm{P}_{\mathrm{S}} \mathrm{D}\left\{\left(\left[1+\left(\mathrm{T}-\mathrm{M}_{\mathrm{R}}\right) \mathrm{I}_{\mathrm{PR}}\right]-\rho\left[1+\left(\mathrm{M}_{\mathrm{A}}+\mathrm{T}\right) \mathrm{I}_{\mathrm{PR}}\right]\right) \frac{\partial^{2} \mathrm{~A}_{1}}{\partial \rho^{2}}-\right. \\
& \left.2\left[1+\left(\mathrm{T}+\mathrm{M}_{\mathrm{A}}\right) \mathrm{I}_{\mathrm{PR}}\right] \frac{\partial \mathrm{A}_{1}}{\partial \rho}\right\}
\end{aligned}
$$

and

$\frac{\partial^{2} \mathrm{Net} 2}{\partial \rho^{2}}=\mathrm{P}_{\mathrm{S}} \mathrm{D}\left(\frac{\partial^{2} \mathrm{~A}_{1}}{\partial \rho^{2}}-\left(1+\left(\mathrm{M}_{\mathrm{A}}+\mathrm{T}\right) \mathrm{I}_{\mathrm{PR}}\right)\left(2 \frac{\partial \mathrm{A}_{1}}{\partial \rho}+\rho \frac{\partial^{2} \mathrm{~A}_{1}}{\partial \rho^{2}}\right)\right)$

$=\mathrm{P}_{\mathrm{S}} \mathrm{D}\left(\left[1-\rho\left(1+\left(\mathrm{M}_{\mathrm{A}}+\mathrm{T}\right) \mathrm{I}_{\mathrm{PR}}\right)\right] \frac{\partial^{2} \mathrm{~A}_{1}}{\partial \rho^{2}}-2\left(1+\left(\mathrm{M}_{\mathrm{A}}+\right.\right.\right.$

T) $\left.\mathrm{I}_{\mathrm{PR}}\right) \frac{\partial \mathrm{A}_{1}}{\partial \rho}$ )

where using (29)

$\frac{\partial^{2} A_{1}}{\partial \rho^{2}}=-2 a b\left[1-2 b(\rho-c)^{2}\right] e^{-b(\rho-c)^{2}}$

$\frac{\partial^{2} \mathrm{~A}_{1}}{\partial \rho^{2}}<0$, if $1-2 \mathrm{~b}(\rho-\mathrm{c})^{2}>0$

i.e., $\frac{1}{2 b}>(\rho-c)^{2}$, i.e. for the range $\rho<c \pm \sqrt{\frac{1}{2 b}}$

Both Net 1 and Net 2 are concave function of $\rho$ if $A_{1}$ is a convex decreasing function of $\rho$.

Note: The conditions derived above are sufficient conditions. Net1 and Net 2 may be a concave function of $\rho$ even if these conditions are not satisfied.

Concavity of $\operatorname{Netj}(j=1,2)$ with respect to $T, P_{R}$ and $\rho$, respectively can be easily seen from the following figures with $\mathrm{A}_{1}$ as defined here,

\section{NUMERICAL EXAMPLES}

In this section, we provide a numerical example each to illustrate the concavity of Netj, $\mathrm{j}=1,2$ under 3 scenarios obtained in Sections (3.2.1) - (3.2.3)
Example 1: Let $\alpha=1000000, \beta=2, \mathrm{~h}=.65, \mathrm{~A}=50, \mathrm{I}_{\mathrm{ER}}=$ $0.06, \mathrm{I}_{\mathrm{PR}}=0.09, \mathrm{P}_{\mathrm{S}}=5, \mathrm{M}_{\mathrm{R}}=0.1, \mathrm{M}_{\mathrm{A}}=0.04, \mathrm{a}=.5, \mathrm{~b}=.9$, $\mathrm{c}=2$ be the parameter values in proper units of the inventory system. Plots of Net1 and Net2 with respect to T for case $I\left(T \geq M_{R}\right)$ and case II $\left(T<M_{R}\right)$ are presented in fig. 1(I) and fig. 1(II) respectively. From the figures, it is clear that for this set of input parameters, Net is a concave function of $\mathrm{T}$ for both the cases. Case II provides larger value of Net.

Given $P_{R}=10, \rho=0.4$, the optimal values of the decision variable are

$\mathrm{T}_{1}^{\#}=0.113$ and $\mathrm{Net}_{1}^{\#}=58503$ when $\mathrm{M}_{\mathrm{R}} \leq \mathrm{T}$ whereas when $M_{R}>T$, the optimal values of the decision variables are $T_{2}{ }^{\#}=$ 0.086 and $\mathrm{Net}_{2}{ }^{\#}=58510.3$ Hence, $\mathrm{T}^{\#}=0.086$ and $\mathrm{Net}^{\#}$ $=58510.3$

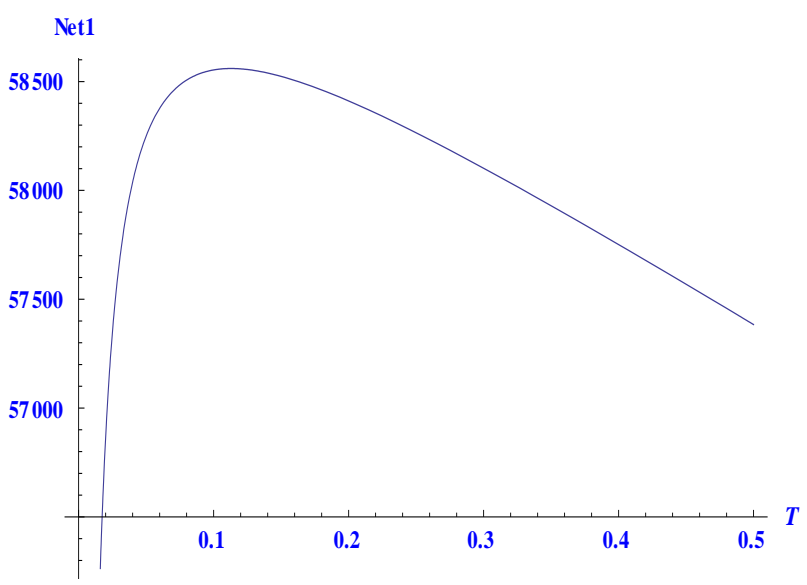

Fig. 1(I): Net versus $T$ for $M_{R} \leq T$

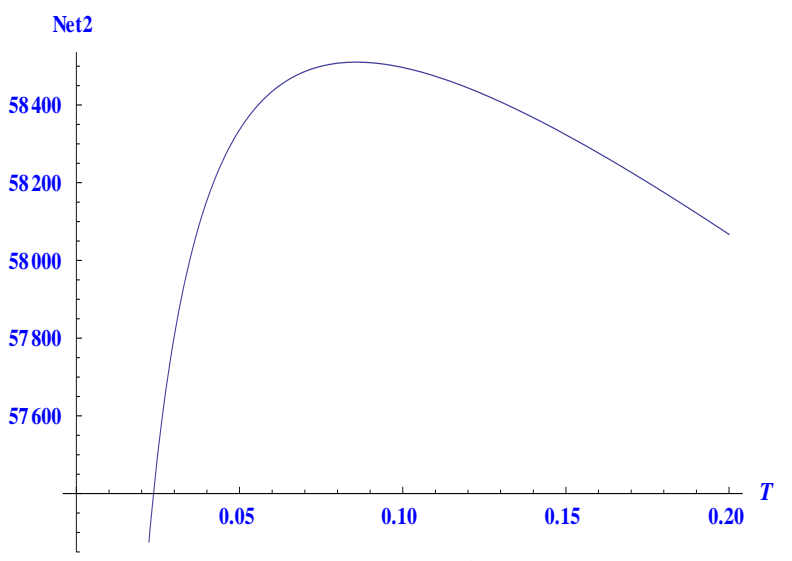

Fig. 1(II): Net versus $\mathrm{T}$ for $\mathrm{M}_{\mathrm{R}}>\mathrm{T}$ 
Example 2: Let $\alpha=1000000, \beta=2, \mathrm{~h}=.65, \mathrm{~A}=50, \mathrm{I}_{\mathrm{ER}}=$ $0.06, \mathrm{I}_{\mathrm{PR}}=0.09, \mathrm{P}_{\mathrm{S}}=5, \mathrm{M}_{\mathrm{R}}=0.1, \mathrm{M}_{\mathrm{A}}=0.04, \mathrm{a}=.5, \mathrm{~b}=.9$, $\mathrm{c}=2$ are parameter values in proper units of the inventory system. The optimal values of the decision variable $\mathrm{P}_{\mathrm{R}}{ }^{\#}$ and Net $^{\#}$ given $\mathrm{T}=.113, \rho=0.4$ are 8.25 and 60363.6 respectively when $M_{R} \leq T$ wherein in $M_{R}>T$ the optimal values of the decision variable $\mathrm{P}_{\mathrm{R}}{ }^{\#}$ and $\mathrm{Net}^{\#}$ given $\mathrm{T}=.086$, $\rho=0.4$ are 8.22 and 60439.4 respectively. Case II provides larger value of Net. Hence, the list for Case II provides the optimal set of values. Plots of Net1 and Net2 with respect to $\mathrm{T}$ for case $\mathrm{I}\left(\mathrm{T} \geq \mathrm{M}_{\mathrm{R}}\right)$ and case II $\left(\mathrm{T}<\mathrm{M}_{\mathrm{R}}\right)$ are presented in Fig. 2(I), Fig. 2(II) respectively. From the figures, it is clear that for this set of input parameters, Net is a concave function of $\mathrm{T}$ for both the cases.

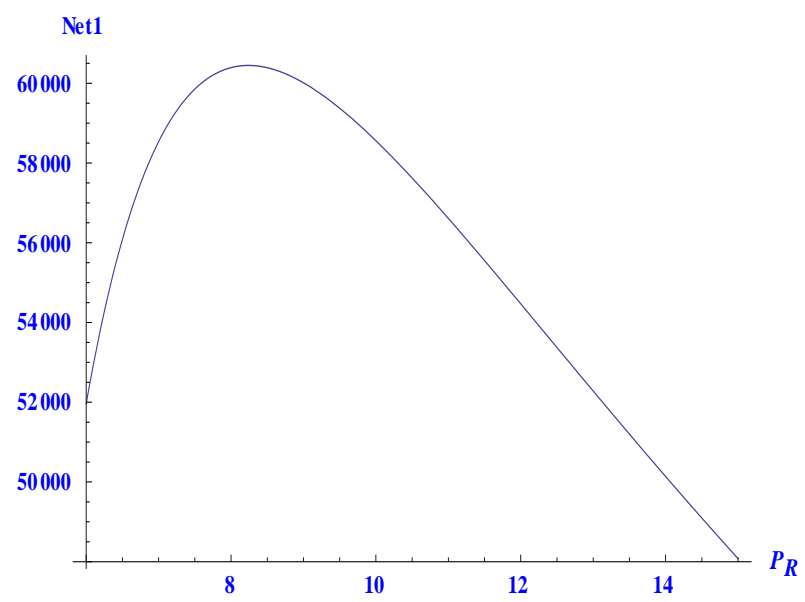

Fig. 2(I): Net versus $P_{R}$ for $M_{R} \leq T$

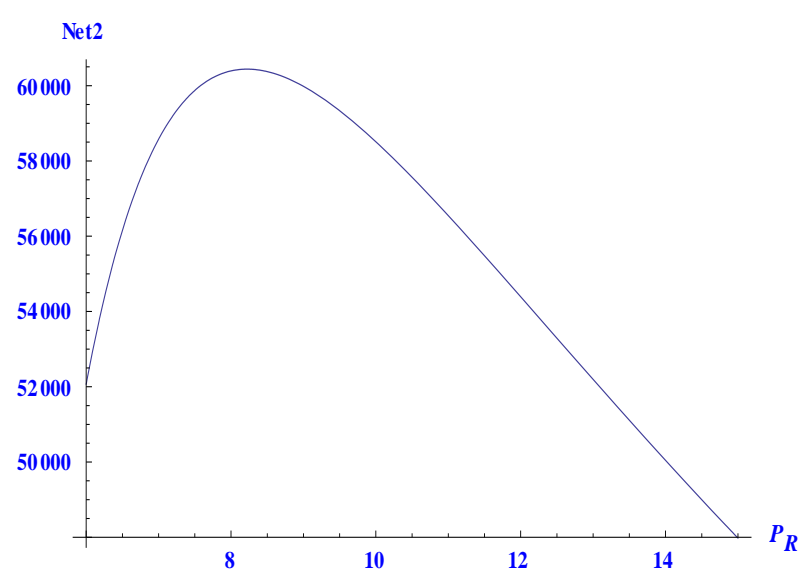

Fig. 2(II): Net versus $P_{R}$ for $M_{R}>T$

Example 3: Let $\alpha=1000000, \beta=2, \mathrm{~h}=.65, \mathrm{~A}=50, \mathrm{I}_{\mathrm{ER}}=$ $0.06, \mathrm{I}_{\mathrm{PR}}=0.09, \mathrm{P}_{\mathrm{S}}=5, \mathrm{M}_{\mathrm{R}}=0.1, \mathrm{M}_{\mathrm{A}}=0.04, \mathrm{a}=.5, \mathrm{~b}=.9$, $\mathrm{c}=2$ are parameter values in proper units of the inventory system. The optimal values of the decision variable $\rho^{\#}$ and
Net $^{\#}$ given $P_{R}=10, T=0.113$ are 0.44 and 58560.1 respectively when $M_{R} \leq T$ wherein in $M_{R}>T$ the optimal values of the decision variable $\rho^{\#}$ and Net $^{\#}$ given $P_{R}=10, T$ $=0.086$ are 0.44 and 58568.9 respectively. Case II provides larger value of Net. Hence, the list for Case II provides the optimal set of values. Plots of Net1 and Net2 with respect to $T$ for case I $\left(T \geq M_{R}\right)$ and case II $\left(T<M_{R}\right)$ are presented in Fig.3(I), and Fig.3(II) respectively. From the figures, it is clear that for this set of input parameters, Net is a concave function of $\mathrm{T}$ for both the cases.

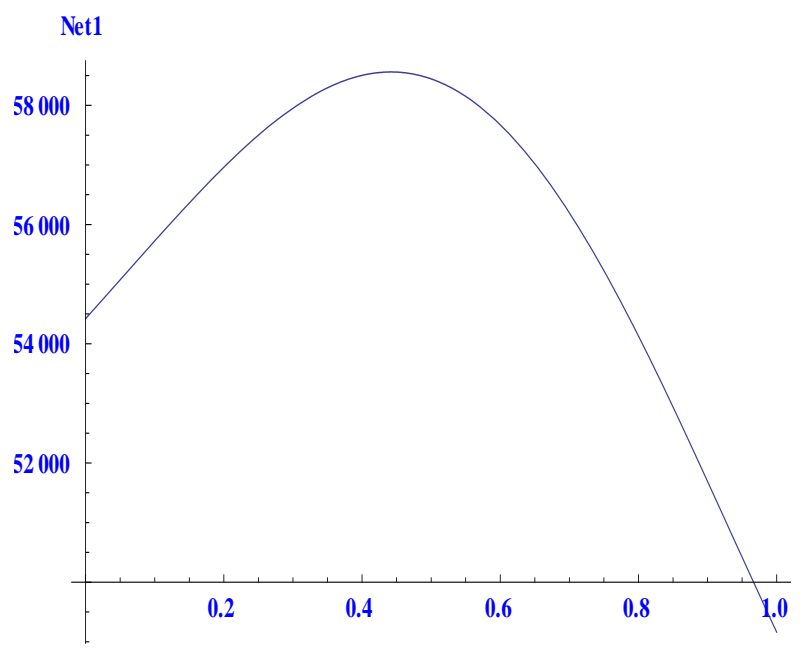

Fig. 3(I): Net versus $\rho$ for $M_{R} \leq T$

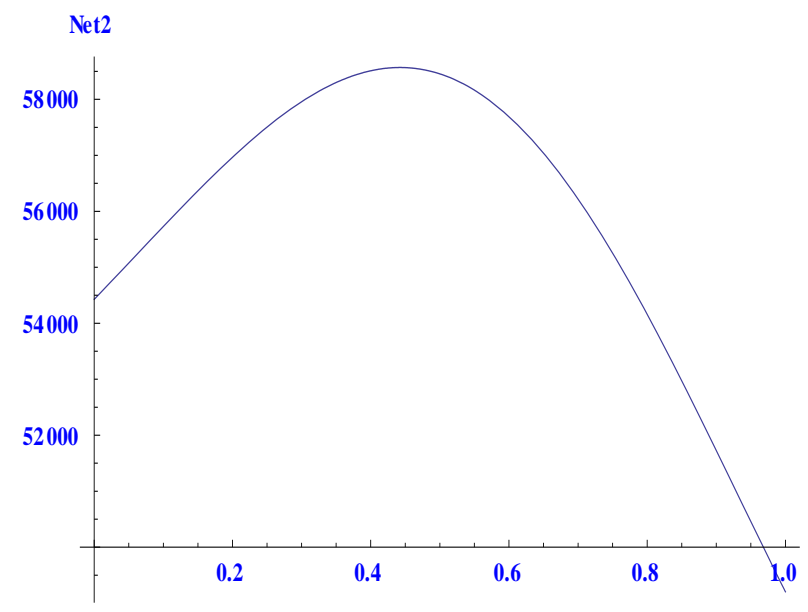

Fig. 3(II): Net versus $\rho$ for $M_{R}>T$

\section{CONCLUSION and Future Scope}

In this paper, we have discussed a payment policy for dominant retailer in an EOQ framework with permissible 
delay in payment. We have also included a reasonable partial advance payment at a discounted price under three different scenarios to model restricted options in real life. In scenario $\mathrm{I}$, the retailer is provided the fixed mark-up price for selling the goods and the discount factor for the payment to be made at the time of advance booking to the supplier. It is shown that the net profit per unit time is a concave function of the cycle length. and the optimal value of the cycle length has been obtained. In scenario II, the discount factor on supplier's selling price for advance payment is specified by the supplier-and the length of the replenishment cycle is fixed, the optimal retailer's selling price has been obtained. In scenario III for the retailer's fixed mark-up price (RFM) and the fixed length of the replenishment cycle is known, the optimal value of the discount factor for the advance payment by the retailer has been obtained. It is clear from the numerical solutions that the policy for the retailer will be beneficial in the II scenario as it corresponds to the maximum net profit when the retailer is provided the information regarding the discount factor given by the supplier under the fixed cycle length. Thus, pricing has emerged as the best possible option, followed by retailer's choice of discount if retailer's selling price and length of replenishment cycle are both exogenous.

Acknowledgement: The authors wish to thank the reviewers for their constructive comments.

\section{REFERENCES}

[1] C.W. Haley, R.C. Higgins, "Inventory policy and trade credit financing", Management Science, Vol. 20, No., 4, pp. 464-471, 1973.

[2] C.B. Chapman, S.C. Ward, D.F. Cooper, M.J. Page, "Credit policy and inventory control", Journal of the Operational Research Society, 35, 1005-1065, 1984.

[3] S.K. Goyal, "Economic order quantity under conditions of permissible delay in payments", Journal of the Operational Research Society, 36, 335-338, 1985.

[4] C.K. Jaggi, S.P. Aggarwal, "Credit financing in economic ordering policies of deteriorating items", International Journal of Production Economics, Vol. 34, No., 2, pp. 151-155, 1994.

[5] M. Khouja, A. Mehrez, "Optimal inventory policy under different supplier credit policies", Journal of Manufacturing Systems, Vol. 15, No., 5, pp. 334-339, 1996.

[6] M.C. Cheng, C.T. Chang, L.Y. Ouyang, "The retailer's optimal ordering policy with trade credit in different financial environments", Applied Mathematical Computations, 218 (19), 9623-9634, 2012.

[7] L.Y. Ouyang, C.H. Ho, C.H. Su, "Optimal strategy for the integrated vendor-buyer inventory model with adjustable production rate and trade credit", International Journal of Information and Management Science, 16, 19-37, 2005.

[8] S.K. Goyal, J.T. Teng, C.T. Chang, "Optimal ordering policies when the supplier provides a progressive interest scheme," European Journal of Operational Research, 179, 404-413, 2007.

[9] C.H. Ho, L.Y. Ouyang, C.H. Su, "Optimal pricing, shipment and payment policy for an integrated supplier-buyer inventory model with two-part trade credit", European Journal of Operational Research, 187, 496-510, 2008.
[10] S.S. Sana, K.S. Chaudhuri, "A deterministic EOQ model with delays in payments and price-discount offers," European Journal of Operational Research, 184, 509-533, 2008.

[11] K. Skouri, I. Konstantaras, S. Papachristos, J.T. Teng, "Supply chain models for deteriorating products with ramp type demand rate under permissible delay in payments" Expert System Applications, 38 (12), 14861-14869, 2011.

[12] M.S. Chern, Y.L. Chan, J.T. Teng, S.K. Goyal, "Nash equilibrium solution in a vendor-buyer supply chain model with permissible delay in payments", Computers and Industrial Engineering, vol. 70, pp. 116-123, 2014.

[13] A.A. Taleizadeh, D. W. Pentico, M. S. Jabalameli, M. Aryanezhad, "An EOQ model with partial delayed payment and partial backordering”, Omega, 41, 354-368, 2013.

[14] Guria, B. Das, S. Mondal, M. Maiti, "Inventory policy for an item with inflation induced purchasing price, sell price and demand with immediate part payment", Applied Mathematical Modelling, 37, 240-257, 2013.

[15] J. Wu, Y.L. Chan, "Lot-sizing policies for deteriorating items with expiration dates and partial trade credit to credit-risk customers" International Journal of Production Economics, 155, 292-30, 2014.

[16] S. C. Chen, J.T. Teng, "Retailer's optimal ordering policy for deteriorating items with maximum lifetime under supplier's trade credit financing", Applied Mathematical Modelling, 2014.

[17] A.X. Zhang, "Optimal advance payment scheme involving fixed per-payment costs", Omega, 24 (5), 577-582, 1996.

[18] A.K. Maiti, M.K. Maiti, M. Maiti, "Inventory model with stochastic lead-time and price dependent demand incorporating advance payment", Applied Mathematical Modelling, 33, 24332443, 2009

[19] A.A. Taleizadeh, S. T. A. Niaki, R. Nikousokhan, "Constraint multiproduct joint-replenishment inventory control problem using uncertain programming", Applied Soft Computing, 11, 51435154,2011

[20] Thangam, "Optimal price discounting and lot-sizing policies for perishable items in a supply chain under advance payment scheme and two-echelon trade credits", International Journal of Production Economics, 139, 459-472, 2012.

[21] A.A. Taleizadeh, H. M. Wee, et al., "Revisiting a fuzzy rough economic order quantity model for deteriorating items considering quantity discount and prepayment", Mathematical and Computer Modelling, 57, 1466-1479, 2013a.

[22] A.A. Taleizadeh, D. W. Pentico, S. Jabalameli, M. B. Aryanezhad, "An economic order quantity model with multiple partial prepayments and partial backordering", Mathematical and Computer Modelling, 57, 311-323, 2013b.

[23] A.A. Taleizadeh, D. W. Pentico, S. Jabalameli, M. B. Aryanezhad, "An EOQ model with partial delayed payment and partial backordering", Omega, 41, 354-368, 2013c.

[24] Q. Zhang, Y.C. Tsao, T.H. Chen, "Economic order quantity under advance payment", Applied Mathematical Modelling, 38(24), 5910-5921, 2014.

[25] A.A. Taleizadeh, "An economic order quantity model for deteriorating item in a purchasing system with multiple prepayments", Applied Mathematical Modelling, 38, 5357-5366, 2014a.

[26] A.A. Taleizadeh, "An EOQ model with partial backordering and advance payments for an evaporating item", International Journal of Production Economics, 155, 185-193, 2014b.

[27] N.P. Zia, A.A. Taleizadeh, "Lot-sizing model with backordering under hybrid linked-to-order multiple advance payments and delayed payment", Transportation Research, E 82, 19-37, 2015.

[28] M. Lashgari, A.A. Taleizadeh, S.S. Sana, "An inventory control problem for deteriorating items with back-ordering and financial considerations under two levels of trade credit linked to order 
quantity", Journal of Industrial \& Management Optimization, 12 (3), 1091-1119, 2016.

[29] A.A. Taleizadeh, "Lot-sizing model with advance payment pricing and disruption in supply under planned partial backordering", International Transactions in Operational Research, 24(4), 783-800, 2017.

[30] J. Wu, J.T. Teng, Y.L. Chan, "Inventory policies for perishable products with expiration dates and advance-cash-credit payment schemes", International Journal of Systems Science: Operations and Logistics, 1-17, 2017.

[31] R. Li, K. Skouri, J.T. Teng, W.G. Yang, "Seller's optimal replenishment policy and payment term among advance, cash, and credit payments", International Journal of Production Economics, 197, 35-42, 2018.

\section{AUTHORS PROFILE}

Rajesh Gupta is an Assistant Professor in Department of Computer Applications, Prestige Institute of Management, Gwalior, India. He obtained M.Sc. degree from Devi Ahilya University, Indore, India. $\mathrm{He}$ is currently pursuing research in Statistics from School of Statistics, Devi Ahilya Vishwavidyalaya, Indore, India. His major research interest includes inventory models related to supply chain. $\mathrm{He}$ has presented papers are in various national and international conferences.

Dr Snigdha Banerjee is a Professor at the School of Statistics, Devi Ahilya University, Indore, India. She has published papers in the fields of operations research, bioinformatics and design of experiments in journals like Journal of the Operational Research Society, International Transactions in Operational Research, Annals of the Institute of Mathematical Statistics, Applied Mathematical Modeling, International Journal of Production Economics, Computers and Industrial Engineering, Mathematical and Computers Modeling, Sankhya, Proteomics, etc. She has also authored a book and has been instrumental in the development of a RDBMS software package. Her current interest is mostly on various aspects of Inventory Management

Dr. Swati Agrawal is Assistant Professor in Department of Mathematics, MB Khalsa College, Indore, India. She obtained her BSc and MSc degrees from Devi Ahilya University, Indore, India. She has published papers in Journals like International Transactions in Operational Research, International Journal of System Sciences and Applied Mathematical Modeling. Her area of research is Inventory Management of deteriorating items and multiple warehouses. Her current interests include inventory models for freshness dependent demand. 